\title{
The Challenges of HIV/AIDS Criminal Legislation in Botswana
}

\author{
ZeinKebonang \\ Operations Director, Botswana-UPenn Partnership, University of Pennsylvania \\ P.O. Box AC 157 ACH, Gaborone, Botswana \\ Tel: 267-7233-7971/7132-7941Ｅ-mail: zkebonang@hotmail.com
}

$\begin{array}{lc}\text { Received: December16, } 2011 \quad \text { Accepted: January5, } 2012 \quad \text { Published: March 1, } 2012 \\ \text { doi:10.5539/jpl.v5n1p189 } & \text { URL: http://dx.doi.org/10.5539/jpl.v5n1p189 }\end{array}$

\begin{abstract}
In an attempt to halt the spread of the HIV epidemic, the Government of Botswana amended in 1998the country's criminal code to provide for stiffer penalties for those charged and convicted of the offence of rape. In particular, there was to be compulsory HIV testing of perpetrators and much stiffer sentences for those who tested positive to the HIV virus. In this paper, I argue that the amendment not only vitiates the right to voluntarily submit to an HIV test, it invades the right to privacy and leads to unwarranted disclosure of confidential information. In addition, I contend that the punitive criminal sentences that follow a positive HIV test are not an appropriate way of preventing transmission as these are not likely to encourage people to voluntarily test for HIV. Punitive sanctions are only justified where it can be shown that a person acted intentionally to transmit the disease.
\end{abstract}

Keywords: Botswana, HIV/AIDS criminalization, Rape, Privacy, Confidentiality, Consent

\section{Introduction}

Apart from its renowned mineral worth, particularly diamonds, Botswanaalso has one of the highest HIV prevalence rate in the world. With a population of 2 million, it is estimated that 350,000 citizens are infected with HIV and/or living with HIV/AIDS, representing about 17 percent of the general population. A number of programs such as the national antiretroviral treatment program which involve making available free antiretroviral therapy (ART) to all eligible citizens have been initiated by government. These efforts have been complimented by assistance from the African Comprehensive HIV and AIDS Partnerships (ACHAP) and the U.S President's Emergency Plan for Aids Relief (PEPFAR). Despite these efforts, HIV continues to be a threat and prevention remains a priority. With the HIV prevalence rate continuing to rise, calls are and have been made to introduce legislation that would mandate partners to reveal their HIV status and to criminalize HIV/AIDS transmission. In considering the merits or otherwise of these calls, this paper starts by reviewing the state of HIV/AIDS in Botswana; it then considers the case for criminalization of HIV/AIDS transmission. This is followed bya brief overview of the HIV criminal legislation in Botswana; the right to privacy and confidentiality before drawing a conclusion.

\section{HIV/AIDS Prevalence in Botswana}

Botswana has and continues to experience one of the most severe HIV/AIDS epidemics in the world (UNAIDS 2002). The national HIV prevalence rate among adults aged between 15 to 49 years is 24.1 percent, which is among the highest in sub-Saharan Africa. Out of a population of 2 million, a third of the adult population is HIV positive (UNAIDS 2002; Negin 2005). The results of the 2008 HIV/AIDS Impact Survey as shown in Table 1 below indicate that the national prevalence rate increased by 0.5 per cent from 17.1 percent in 2004 to 17.6 percent in 2008(Note 1). Although a modest increase, the burden of HIV in Botswana continues to increase as a result of new infections and people on antiretroviral treatment therapy (ART) living longer. As Table 1 demonstrates, although the 2008 prevalence rates for ages 10-34 had declined, the same could not be said for the prevalence in the 35-65 age categories.

[Table 1 about here]

Despite the overall increase in the prevalence rate, Botswana's institutional response to HIV/AIDS has been a strong one. In 1999 the country established the prevention of mother to child transmission program(Note 2)(PMTCT). This program was followed in 2002 by the establishment of the National AIDS Council (NAC). Headed by Ian Khama, the President of the Republic of Botswana, the council is made up of representatives from across government, civil society organizations and the private sector(Note 3). A six year National Strategic Framework (NSF) for HIV/AIDS was formulated in 2003 to define goals; provide guidelines and to spell out what the national response to the 
epidemic should be (Note 4). Equally, collaborative efforts have been established with a number of partner institutions to help fight the pandemic. Key partner institutions have included the Botswana-UPenn Partnership, the African Comprehensive HIV/AIDS Partnership (ACHAP) which is a public-private partnership established in 2000 between the Government of Botswana, the Bill and Melinda Gates Foundation and the Merck Company Foundation; the BOTUSA Project (funded through PEPFAR), and the Botswana-Harvard Project.

In addition to the above initiatives, the country became the first African country to provide free antiretroviral drugs (ARVs) to all eligible persons. According to the 2010 United Nations AIDS Agency Report (UNAIDS), the provision of antiretroviral therapy in Botswana has resulted in the annual number of AIDS-related deaths declining by half from 18000 in 2002 to 9100 in 2009, while the estimated number of children newly orphaned by AIDS has fallen by 40 percent (UNAIDS 2010a). Similarly, the extensive provision of antiretroviral therapy has averted an estimated 50000 adult deaths. If the momentum is maintained, it is anticipated that a further 130000 deaths will be averted by 2016 (UNAIDS 2010a).

The ARV roll out has been incredibly successful with over 90 percent of those needing HIV treatment receiving it. However, the country continues to suffer greatly from the HIV/AIDS pandemic. Despite warnings by health authorities on the negative effects of pregnancy when one is HIV positive, such incidents persist. Although the number of children born with HIV/AIDS infection declined from 4600 in 1999 to 890 in 2008, the decline came largely because of the successful implementation of the prevention of mother-to-child transmission program (PMTCT) (Stover, Fidzani, Molomo, Moeti, Musuka 2008) and not because of changes in sexual behavior. Instances have also been reported were some men fully aware of their status have deliberately exposed their partners to the HIV virus(Note 5). It is for this reason that calls have been made by the general public for the criminalization of HIV transmission in Botswana.

\section{A Case for Criminalization of HIV/AIDS Transmission}

In September 2004, at a workshop funded by United States Aid Agency (USAID), a number of West and Central African countries came together in N'Djamena, Chad, to develop a model law on HIV/AIDS (Note 6). As a template, the countries hoped that the Model law would provide a basis for either enacting or reforming HIV/AIDS legislation across west and central Africa. Countries such as Benin, Guinea, Mali, Niger, Sierra Leone, Togo and Guinea-Bissau have since moved to adopt the Model law as part of their national law (Pearshouse 2007). While the Model law provides for preand post counseling and guarantees health care services for people living with HIV/AIDS (Note 7), the requirement for consent for HIV testing (Note 8), confidentiality (Note 9) and non-discrimination (Note 10), its most salient feature is its criminalization of HIV/AIDS transmission (Note 11).

Criminalization of HIV transmission has found favor in a number of jurisdictions (Note 12). In the United States for instance, 24 states have laws that make it a crime for persons who have HIV to engage in various sexual behaviors without disclosing their HIV-positive status to prospective sex partners (Gallety, Pinkerton 2008; 2006). In Canada too, it is a criminal offence to transmit or expose others to the risk of infection with HIV through unprotected sex (Merninod 2009). Apart from a great deal of thoughtfulness on the issue of HIV/AIDS criminalization, these countries also place high value on human rights and autonomy and therefore offer significant insight on the issue. Be this as it may, proponents of criminalization argue that criminal law not only deters HIV-positive individuals from risk taking behavior but also punishes them for placing others at risk of infection (Merninod 2009). Deterrence as a rational for punishing HIV transmission was succinctly articulated by the Canadian Supreme Court in the case of $R$. v. Cuerrie as follows;

"[criminal] law provides a needed measure of protection in the form of deterrence and reflects society's abhorrence of the self-centered recklessness and the callous insensitivity of the actions of the respondent and those who have acted in a similar manner. The risk of infection and death of partners of HIV-positive individuals is a cruel and ever present reality. Indeed the potentially fatal consequences are far more invidious and graver than many other actions prohibited by the Criminal Code. The risks of infection are so devastating that there is a real and urgent need to provide a measure of protection for those in the position of the complainants. If ever there was a place for the deterrence provided by criminal sanctions it is present in these circumstances. The Criminal Code does have a role to play. Through deterrence it will protect and serve to encourage honesty, frankness and safer sexual practices." (cited in Merninod 2009).

Those opposed to criminalization however maintain that the potential to be charged with wilful HIV transmission may be a significant deterrent to being tested for HIV infection. Burris and Cameron (2008) contend for instance that criminalization of HIV is inconsistent with good public health and respect for human rights. They argue that the 
use of criminal law to address transmission of HIV is inappropriate except in cases in which it can be shown that a person acted with the conscious intent to transmit HIV and in fact did so. The challenge with criminal legislation however lies in drawing the line between criminal and noncriminal behavior, which in turn depends on a blameworthy state of mind (Burris and Cameron 2008). In the absence of this intention, it would be difficult to extend a criminal sanction to somebody who while exposing or infecting another was not aware of his/her own status. Thus, while it may be appealing to some individuals and governments to criminalize HIV transmission and exposure as a means of addressing the spread of HIV, criminalization actually undermines public health goals and violates the rights of people living with HIV (Burris and Cameron 2008). According to UNAIDS (2010b), the criminalization of HIV/AIDS does not achieve either criminal justice or prevent transmission but rather undermine public health and human rights. Consequently, criminal law is not to be used beyond cases of intentional transmission if prevention efforts are not to be undermined Note 13).

\section{HIV/ AIDS Legislation in Botswana}

Despite public pressure and the high prevalence rate of HIV/AIDS in Botswana, the country has not adopted any HIV-specific criminal legislation. This notwithstanding, the government has sought to prosecute transmission of HIV/AIDS in a roundabout way. In 1998, Parliament with the intention of addressing the escalation of rape cases in the country amended the Penal Code (Note 14) to provide for stiffer penalties for those charged with the offence of rape and for a mandatory HIV/AIDS test of those convicted of the offence. Any person convicted of the offence of rape is required before sentencing to undergo an HIV/AIDS test (Note 15). A person who testspositive is liable for an imprisonment term of 15 years but only if he was unaware of his HIV status at the time of the offense (Note 16). If it is established however that the person was aware of his positive HIV status, then, such a person can be sentenced to a minimum of 20 years imprisonment with corporal punishment (Note 17).

One of the shortcomings with this law is that it assumes that transmission only occurs through rape. The reality is that transmission occurs through a number of ways such as consensual sexual relations, multiple sex partners and excessive consumption of alcohol leading to unprotected sexual conduct, with rape accounting for a small number of cases. This is particularly the case as available rape statistics show that in 2010 , there were only 862 rape cases reported to the police (Note 18). This is clearly an insignificant number that cannot account for a third of the population being HIV positive. Without much basis, the law also assumes that a convicted rapist who turns out to be HIV positive must have been positive at the time the offence was committed. It would appear that the main reason for the law was to punish those that intentionally infected others as a form of wilful malfeasance.

Although a rape victim can access treatment at any of the state hospitals if the rape is reported immediately and criminal charges are laid within 72 hours of the alleged event happening, often rape cases are either unreported or there are delays in reporting them. Even in instances where there are no delays in reporting the rape, the lack of medical services, particularly in rural areas and outlying settlements means that victims are unable to have access to health care services in a timely manner. Consequently, victims are not offered HIV testing at the time of reporting the crime and may not be offered it until much later. Those accused of rape may also not be prosecuted until much later.

Further, the practical challenges associated with testing after rape is that it may be very difficult to establish temporal causality between rape and HIV transmission for at least three (3) reasons. First, the victim's status at the time of the crime cannot be known with certainty unless she had a prior HIV test and no other high risk activity. Second, the natural history of HIV disease means that a person may test negative at the time of rape but only sero-convert three (3) months later. Third, the rapist status at the time of crime may not be known in some instances. Even if an accused person tested positive at the time of rape, the question that arises is whether they knew they were positive and if they did, did they have sufficient health literacy to understand the implications of their positive status. Thus, unless sophisticated diagnostic tests (viral load arrays) are performed immediately after the rape, it is almost difficult to establish causality because of the intervening period or "sero-conversion" window. In a country where the criminal justice system moves very slowly, where it is not unheard of for criminal trials to take between 3-5 years to conclude, sentencing based on one's HIV status can only result in prejudice and injustice as it does not account for the intervening period between the time the offence was reported and the start and completion of the criminal trial. Complicating the matter is the fact that an accused person is never compelled to submit to an HIV/AIDS test at the time when the offence is reported to the police. It may well be that the victim was already HIV positive at the time the offence took place. A correct approach therefore would be one, which entails an enquiry into the HIV status of the rape victim before the rape occurred. As Burris and Cameron (2008) point out, in an overwhelming majority of cases, HIV is not spread by criminals but by consensual participants in a sexual act neither of whom knowing their HIV status. 
Even though the 1998 Amendment punishes intentional transmission by imposing a severe sentence of 20 years, the 2008 Botswana Aids Impact Studies reveal that 56.4 percent of the population (aged between 10-64 years) had never taken an HIV test and that of those aged between 15-49 years who were involved in casual sexual relationships only six per cent reported using condoms (Note 19). Given these statistics, the general reluctance on the part of the public to undergo voluntary HIV testing and attitude towards condom use, the value of imposing severe sentences appears suspect. Equally, the value of imposing corporal punishment on an HIV positive inmate appears to serve no purpose other than being purely retributive. Article 10 of the International Covenant on Civil and Political Rights (ICCPR) enjoins states to treat all persons deprived of their liberty with humanity and with respect for the inherent dignity of the human person. The administration of corporal punishment is counter to the dignity required to be accorded HIV positive inmates.

Although the 1998 Amendment was in part intended to address the question of transmission of HIV, our courts have been reluctant to apply the law blindly. In the case of State v OntshabetseLejony (Note 20), the accused person had been convicted of the offence of rape and on being tested for HIV/AIDS, tested positive. The case was committed to the High Court for sentencing, as the trial court had no jurisdiction to impose the enhanced minimum sentence of 15 years. The Court in refusing to impose the minimum sentence of 15 years considered in its ruling the meaning to be attached to the words "that such a person was unaware of being Human Immune Virus Positive". The court held that in order for it to be proven that a convicted person was unaware of being HIV positive, it ought to be proven that such person was indeed HIV positive at the material time, that is, the time of committing the offence. Consequently, the court imposed a sentence of 10 years prescribed for the offense of rape under the old Act. The court held that Parliament could not have intended to include people who were not at all culpable but merely became so because they happen to be HIV positive after being found guilty. The court also found that the provision in question affected rights and liberties which must in the absence of clarity be given a restrictive interpretation.

The above notwithstanding, wilful and deliberate transmission of HIV must be considered to constitute a violation of the right to life. In such circumstances, severe penal sanctions will be appropriate and perhaps effective measure of controlling transmission of HIV. While not advocating for criminalization of HIV transmission both the UNAIDS report and the Model Law provide that the HIV-positive status of an offender is a legitimate aggravating factor in sentencing only if the person knew he/she was HIV positive at the time of committing the offence. In $\underline{\mathbf{R}} \mathbf{v}$ M'wai (Note 21), the New Zealand Court of Appeal confirmed the decision of a lower court, which had imposed a seven (7) year jail sentence on the accused having tested positive to the AIDS test. In that case the accused had had unprotected sex with a number of women at a time when he knew that he had HIV.

\section{The Right to Privacy and Duty of Confidentiality}

Like many other constitutions, the constitution (Note 22) of Botswana contains a bill of rights. Included in this bill of rights is the right to privacy (Note 23). As a constitutionally guaranteed right, the state cannot abridge the right without justification. The constitutional right to privacy guarantees to the individual the freedom to reject or refuse to consent to the intrusion of his bodily integrity. Although constitutionally guaranteed, the right to privacy is not accorded absolute privilege and may be limited under certain circumstances if it is in the public interest (Note 24). However, in determining whether any invasion of the right to privacy is justifiable, there is need to engage in a balancing exercise between public interest in halting the spread of the AIDS pandemic and the individual's human rights to privacy. An assessment as to the relative value to be attached to these conflicting interests must be made. Thus, laws that disadvantage a particular class are constitutional only when their adverse impacts may reasonably be viewed as acceptable cost of achieving a larger goal. Intruding on the right of privacy in order to limit the spread of HIV/AIDS is only justifiable if it can be shown that a person knowingly transmitted the HIV virus.

The rational for HIV/AIDS criminalization in Botswana seems to be two fold; to serve as a deterrent and as a form of punitive intervention. A disturbing aspect however of the 1998 Amendment is its breach of the right to privacy and confidentiality. An imposition of either a 15 or 20 year jail sentence is tantamount to a disclosure of confidential information as it confirms one's HIV status. Further, the mandatory HIV test required of those convicted of rape does not only amount to an unwelcome invasion of the right to privacy but also leads to unwarranted disclosure of private medical tests. Such a disclosure is inconsistent with the provisions of the Public Health Act (Note 25). The Public Health Act, which makes notification of certain diseases compulsory, does not classify HIV/AIDS as a notifiable disease requiring disclosure. In my view, society must, in protecting those who are not affected by HIV/AIDS, also protect the rights and dignity of those infected by the virus. Accurate information concerning HIV/AIDS and sexually transmitted diseases (STDs), counseling and non-discriminatory access to medical care must be given to both the perpetrator and the victim to ensure that they are both treated humanely and with dignity.

The need for both the victim and perpetrator to receive care is important as the 1998 Amendment does not provide 
for the victim or perpetrator to receive Post Exposure Prophylaxis (PEP) treatment. In the US for instance, the recommendation is to start PEP at the time of rape. Whether the individual continues the 28 days or 3 months course is dependent on whether the rapist test positive when tested. Subjecting the perpetrator to an HIV/AIDS test at the time the offence is reported and not after their conviction, may enable the survivor or victim to make informed decisions about their need for PEP. Doing so only years later when a criminal trial is concluded may be too late to afford the victim viable treatment options. Ultimately, because of its psychological effect, the disclosure of one's HIV status may neither be in the interest of the accused or the complainant primarily because a positive result leads to distress, stigmatization and isolation of not only the perpetrator but also of the victim. In some countries such as the United States, health measures infringing on the right to privacy, related liberties and bodily integrity have been given strict judicial scrutiny. In South Africa, courts have held that in the case of HIV/AIDS, there are special circumstances justifying the protection of confidentiality as disclosure of the condition has serious personal and social consequences for the person so infected or affected (Note 26).

\section{Consent to HIV/AIDS Testing}

It is submitted that individuals whether HIV/ positive or not, must be allowed to freely and voluntarily submit to an HIV test. This choice premised as it were, on the principle of personal self-governance, - that an individual must freely consent to any test being carried out on his body- finds affirmation in the National Policy on HIV/AIDS (Note 27), which provides that no HIV testing shall be carried out against the will of any individual and that where any test is carried out such must be accompanied by both pre and post- test counseling. The unilateral and coercive nature of the HIV test which is often not accompanied by any counseling for persons convicted of rape is clearly inconsistent with the right of choice and infringes on the right to consent. Knowledge that one is being tested for HIV in itself cannot amount to informed consent nor is it sufficient for a person performing the test to inform the party being tested that the test is for HIV and to ask whether he consented. In my view, those tested for HIV must appreciate how an HIV test will alter their lives and must therefore be given the applicable tools to accept the results.

\section{Conclusion}

The severe penal sanctions for rape, particularly for individuals that find themselves HIV positive as prescribed under the 1998 Amendment appear to be more about retribution and therefore raise doubts about their efficacy in dealing with the problem of HIV transmission. While it may seem desirable to impose punitive sanctions in order to deter transmission, this is likely to be counter-productive as criminal provisions will simply deter people from voluntarily testing for HIV/AIDS. Merely punishing convicted persons for being HIV positive will not help normalize the acceptance of the disease but rather lead to the further marginalization of HIV infected persons. The way to halt the spread of HIV/AIDS in Botswana thereforelies not in the criminalization of transmission but the encouragement of behavioral change. Further, insofar as it leads to disclosure of confidential information and the vitiation of consent, compulsory testing and the punitive criminal sentences that follow a positive HIV test are not an appropriate way of preventing transmission.Punitive sanctions are only justified where it can be shown that a person acted intentionally to transmit the virus. Knowledge that one is being tested for HIV is not enough in the absence of one understanding and appreciating the implications of either a positive or negative result. Intensified public education, getting people to voluntarily test and to practice safe sex, reinforcing positive messages about knowing ones status are desirable to criminalization. Criminalization of transmission can only make people reluctant to test knowing that their lack of knowledge will make them less culpable. Awareness campaigns and strengthening and leveraging on existing collaboration efforts are also essential. So too is a compassionate approach to HIV/AIDS to ensure that people infected by it live their lives in dignity and respect.

\section{References}

Burris, S, \& Cameron, E. (2008). "The Case Against Criminalization of HIV Transmission”, Journal of American Medical Association, Vol. 300, 578-58. http://dx.doi.org/10.1001/jama.300.5.578.

Galletly, C.L, \& Pinkerton, S.D. (2006). "Conflicting Messages: How Criminal HIV Disclosure Undermines Public Health Efforts to Control the Spread of HIV", AIDS Behav, Vol. 10.5, 451-61. http://dx.doi.org/10.1007/s10461-006-9117-3.

Galletly, C.L, \& Pinkerton, S.D. (2008). "Preventing HIV Transmission via HIV Exposure Laws: Applying Logic and Mathematical Modeling to Compare Statutory Approaches to Penalizing Undisclosed Exposure to HIV".J Law Med Ethics.Vol. 36.3; 577-84.http://dx.doi.org/10.1111/j.1748-720X.2008.306.x.

Merninod, A. (2009). "The Deterrence Rational in the Criminalization of HIV/AIDS”, Lex Electronica, Vol. 13.3, $2-30$. 
Negin, J. (2005). "Assessing the Impact on HIV/AIDS on Economic Growth and Rural Agriculture in Africa", Journal of International Affairs, Vol. 13.3, 41-66.

Pearshouse, R. (2007). "Legislation Contagion: The Spread of Problematic new HIV Laws in Western Africa", HIV/AIDS Policy and Law Review, Vol. 12.2/3, 4-11.

Stover J, Fidzani B, Molomo BC. Moeti T, Musuka G. (2008). "Estimated HIV Trends and Program Effects in Botswana". PLoS ONE 3(11): e3729. http://dx.doi.org/10.1371/journal.pone.0003729.

UNAIDS Global Report. (2010a). Geneva, Switzerland.

UNAIDS Policy Brief. (2010b). Criminalization of HIV Transmission. Geneva, Switzerland.

UNAIDS Reporton the Global HIV/Aids Epidemic (2002). UNAIDS/02.26E, Geneva Switzerland.

\section{Notes}

Note 1. See the Botswana Aids Impact Survey III (BAIS III) 2008 Preliminary Result, Central Statistics Office, Gaborone Botswana.

Note 2. The prevention of mother-to-child transmission (PMTCT) program was the first program to distribute antiretroviral drugs in Botswana. Services have been established in all public facilities through the Maternal Child Health/Family Planning system, which serves over 90 per cent of all pregnant women. Current results indicate that less than 4 percent of babies born to HIV positive mothers were infected - a rate comparable with the USA and Western Europe.

Note 3. See; Botswana's National Policy on HIV/AIDS, Ministry of Health, Gaborone, Botswana.

Note 4. National Aids Co-ordinating Agency (NACA) (2003) National Strategic Framework for HIV/AIDS, 2003-2009 (Gaborone: NACA).

Note 5. See; The Echo Newspaper, "AIDS Patients on a killing spree",7th December 2006.

Note 6. The Model Law is essentially a legislative template which individual countries are free to adopt or modify as they deem fit. It provides for a sharing of experiences and prevents duplication of drafting separate laws in each jurisdiction.

Note 7. See; Article 20 Model Law.

Note 8. Article 17 Model Law.

Note 9. Article 24 Model Law.

Note 10. See; Chapter VII Model Law.

Note 11. See Article 36 Model Law.

Note 12. These include among others, New South Wales, China, Vietnam, Denmark, France, Germany, the Netherlands, Norway, Poland, Russia, Sweden, Ukraine and Kenya.

Note 13. This is because criminalization of HIV may drive people away from public health initiatives that have proven effective, such as HIV testing, counseling and support. Further, the public attention given to criminal prosecutions may create a false sense of security that the law will protect people from HIV infection thus undermining the message that every person is responsible for his or her own sexual health.

Note 14. CAB 8:01 Laws of Botswana.

Note 15. Penal Code (Amendment) Act no 5 of 1998.

Note 16. Section 142(3) Ibid.

Note 17. Section 142 (4) a Ibid.

Note 18. See; The Weekly Police Service Crime Report (2010). Botswana Police Service.

Note 19. Note 1 supra.

Note 20. Criminal Trial no 357/99 unreported.

Note 21. (1995) 3 NZLR 149.

Note 22. CAB: 001 Laws of Botswana.

Note 23. See Section 3 Constitution of Botswana.

Note 24. See Proviso to Section 3 Constitution of Botswana. 
Note 25. CAB 63.01, Laws of Botswana.

Note 26. See Jansen Van Vuuren v Kruger 1993 (4), SA 842.

Note 27. The Policy was approved and adopted by Government in 1993 through a Presidential Directive CAB:35/93.

Table 1. Comparison of some Botswana Aids Impact Survey II (BAIS II), 2004 and Botswana AIDS Impact Survey III (BAIS III), 2008, Results

\begin{tabular}{|l|l|l|}
\hline HIV PREVALENCE & 2004 & 2008 \\
\hline Age & & \\
\hline $1.5-4$ & 6.3 & 2.2 \\
\hline $5-9$ & 6.0 & 4.7 \\
\hline $10-14$ & 3.9 & 3.5 \\
\hline $15-19$ & 6.5 & 3.7 \\
\hline $20-24$ & 19.0 & 12.3 \\
\hline $25-29$ & 33.0 & 25.9 \\
\hline $30-34$ & 40.2 & 39.7 \\
\hline $35-39$ & 35.9 & 40.5 \\
\hline $40-44$ & 30.3 & 40.6 \\
\hline $45-49$ & 29.4 & 29.8 \\
\hline $50-54$ & 20.9 & 24.8 \\
\hline $55-59$ & 14.0 & 22.8 \\
\hline $60-64$ & 12.0 & 15.4 \\
\hline $65+$ & 6.8 & 10.4 \\
\hline Total & 17.1 & 17.6 \\
\hline
\end{tabular}

Source: Botswana Aids Impact Survey 2008. 